\title{
Percepção ambiental de alunos do ensino fundamental no município de Tupanciretã/RS
}

\section{Environmental perception of student education students in Tupanciretã/RS}

\author{
Nathália Leal de Carvalho ', Milene Almeida Ribas ", Themis Goretti Moreira Leal de \\ Carvalho '"', Afonso Lopes de Barcellos IV
}

\section{RESUMO}

A Educação Ambiental aguça os meios de percepção e compreensão de fatores que incitam a preservação ambiental, valores que conduzem a preservação ambiental e melhoria do meio em que vivemos. Com o objetivo de avaliar a percepção ambiental de alunos de ensino fundamental de duas escolas, em Tupanciretã/RS. A análise foi baseada em um questionário, sendo posteriormente feita a análise relativa às respostas. Os alunos conhecem os problemas ambientais no Município e do ambiente escolar, têm consciência da importância da mudança de atitudes e hábitos e percebem a importância de se trabalhar a Educação Ambiental a partir da realidade escolar.

Palavras-chave: Educação ambiental; Preservação ambiental; Sustentabilidade.

\begin{abstract}
The Environmental Education sharpens the means of perception and understanding of factors that incite the environmental preservation, values that lead to the environmental preservation and improvement of the environment in which we live. With the objective of evaluating the environmental perception of elementary school students from two schools, in Tupanciretã / RS. The analysis was based on a questionnaire, and the analysis of the answers was then made. The students are aware of the environmental problems in the Municipality and the school environment, are aware of the importance of changing attitudes and habits and realize the importance of working Environmental Education from school reality.
\end{abstract}

Keywords: Environmental education; Environmental preservation; Sustainability.

I Doutora, Professora, Departamento de Estudos Agrários - DEAg, UFSM. E-mail: nathaliiinha@gmail.com. ORCID: http://orcid.org/0000-0002-8256-9406.

" Mestranda do Programa de Pós-Graduação em Reabilitação Funcional, UFSM. E-mail: my-ribas@hotmail.com. ORCID: http://orcid.org/0000-0002-5993-6730.

III Mestre, Professora de Curso de Fisioterapia, UNICRUZ. E-mail: carvalhothemis@gmail.com. ORCID: http://orcid.org/00000003-2440-4301.

IV Contador, Mestre em Desenvolvimento Rural, UNICRUZ. E-mail: lopesdelopes@hotmail.com. ORCID: https://orcid.org/00000003-1190-9474. 


\section{INTRODUÇÃO}

Educação Ambiental (EA) se constitui numa forma abrangente de educação, que se propõe atingir todos os cidadãos. Nas escolas pode ser decisiva para diminuir os problemas que há anos vêm sendo causados ao meio ambiente pela ação do homem. Através de um processo participativo, que procura induzir uma consciência crítica sobre a real situação ambiental, compreendendo-se como crítica a capacidade de captar a gênese e a evolução de problemas ambientais (Silva, 2012).

Com as questões ambientais mais presentes no cotidiano da sociedade, a educação ambiental é fundamental em todos os níveis dos processos educativos e, em especial nos anos iniciais da escolarização, já que é mais fácil conscientizar as crianças, que ainda não possuem hábitos e comportamentos constituídos sobre as questões ambientais do que os adultos (MEDEIROS et al., 2011).

A EA surgiu da necessidade de implementação de uma educação de caráter interdisciplinar, voltada para os problemas atuais e urgentes, que prepara a população para viver e se desenvolver em um mundo interdependente e em harmonia com as leis da natureza e, que abordasse também, de forma global, a busca das soluções (DIAS, 2004). No entanto, a EA é um processo que visa reconhecimento de valores e conceitos. Para o desenvolvimento das habilidades, modificando as atitudes em relação ao meio, para entender as relações entre os seres humanos, suas culturas e seus meios biofísicos.

Cada indivíduo percebe, reage e responde diferentemente às ações sobre o ambiente em que vive. As respostas ou manifestações decorrentes são resultado das percepções (individuais e coletivas), dos processos cognitivos, julgamentos e expectativas de cada pessoa. À medida que adquirimos novas informações, nossa percepção se altera (FERNANDES et al., 2004).

A Percepção ambiental (PA) é "uma tomada de consciência do ambiente pelo homem", ou seja, se auto define compreender o ambiente em que está inserido, aprendendo a proteger, preservar e cuidar da melhor forma possível (COSTA; MAROTI, 2013). Diante disso, o estudo da PA é de fundamental importância para que possamos 
entender melhor as inter-relações entre o homem, ambiente e suas expectativas, satisfações e insatisfações, julgamentos e condutas.

A cada dia que passa a questão ambiental tem sido considerada como um fato no qual precisa ser trabalhada. A escola ainda é o lugar mais adequado para trabalhar a relação homem-ambiente-sociedade, sendo um espaço adequado para formar um homem novo, crítico e criativo, com uma nova visão de mundo que supere o antropocentrismo. É necessário que a escola, enquanto instituição esteja preparada para incorporar a temática ambiental de forma coerente (MEDEIROS et al., 2011).

A determinação da temática ambiental na educação ganhou força, em nível mundial, a partir da proclamação da Década das Nações Unidas da Educação para o Desenvolvimento Sustentável (2005-2014) e, em nível nacional. E, em 2012, com a implantação da EA nos currículos escolares do MEC. A partir de então, foi estabelecido parâmetros para que a EA fizesse parte de todos os níveis educacionais: educação infantil, ensino fundamental, médio, superior, educação especial, quilombola e indígena (FIGUEIRÓ, 2015).

A atual problemática ambiental revela uma crise da própria civilização. Não é a natureza que se encontra em desarmonia é a própria sociedade, pois construímos uma sociedade de risco. É necessário tomar medidas que levem o ser humano a se adaptar com a natureza, estabelecer respeito entre os seres vivos que existem no planeta e aprender a conviver com dignidade, procedendo a favor do bem (BORTOLON; MENDES, 2014).

Com o objetivo de investigar as percepções dos estudantes do Ensino Fundamental de duas escolas públicas, sendo uma Estadual e outra Municipal do município de Tupanciretã/RS, sobre o meio ambiente, identificando as diferenças e buscando identificar as carências e os assuntos que os alunos têm mais interesse, se procedeu a pesquisa. Colaborando para melhorar o ensino da EA nas escolas do Município. 


\section{METODOLOGIA}

O estudo foi desenvolvido no município de Tupanciretã, localizado na região Sul do Brasil e na Mesorregião Centro Ocidental Rio-grandense. Apresenta uma superfície de $2,251.863 \mathrm{Km}^{2}$, situada entre os paralelos de $28^{\circ} 47^{\prime}, 29^{\circ} 12^{\prime}$, de latitude sul e os meridianos $53^{\circ} 34^{\prime}, 54^{\circ} 28^{\prime}$ de longitude oeste, estando a uma altitude de 465 metros e, pertencente ao bioma Pampa. Com uma população estimada de aproximadamente 23.000 habitantes (IBGE, 2010).

Este trabalho tratou de uma pesquisa exploratória a campo, onde se buscou o conhecimento da percepção ambiental dos alunos do ensino fundamental de duas escolas públicas no município de Tupanciretã/RS.

Para análise da percepção ambiental dos estudantes foi utilizado um questionário com 13 perguntas, a respeito de questões ambientais, como a importância da água, florestas, lixos, entre outros. As perguntas foram de livre resposta, a fim de que os alunos pudessem expressar o que realmente entendiam acerca de meio ambiente.

O questionário foi aplicado a 304 alunos matriculados no ano de 2014, do $7^{\circ}$ ao $9^{\circ}$ ano de duas escolas do município, Escola Municipal de Ensino Fundamental (EMEF) Dr. Flory Kruel e Escola Estadual de Ensino Fundamental (EEEF) Antônio Silveira, ambas localizadas na Zona Urbana, mas com alunos oriundos tanto da Zona Urbana como da Rural.

Considerando a variedade de respostas dos alunos que foram obtidas no questionário, para análise deste, foi utilizada a técnica desenvolvida por Vasconcelos (2005) e utilizada por Pereira, Farrapeira e Pinto (2006), adaptando-a para o objeto deste estudo.

Neste sentido, foram criadas três categorias de indicadores de avaliação para as respostas: "Satisfatórias", para aquelas completas, nas quais os alunos demonstraram ter um conhecimento significativo do assunto abordado; "Parcialmente satisfatórias", nas quais os alunos demonstraram ter um conhecimento mínimo do assunto abordado; e "Insatisfatórias", onde os alunos demonstraram ou declararam não saber nada sobre o 
assunto, ou ainda, quando os mesmos deixaram a questão em branco. Através das percentagens das respostas em cada categoria, puderam ser observadas as diferenças nas concepções dos alunos das diferentes séries avaliadas.

\section{RESULTADOS E DISCUSSÃO}

O total de alunos entrevistados na EMEF Dr. Flory Druck Kruel foi de 160 estudantes, sendo que destes $90 \%(n=144)$ residem na zona urbana e 10\% $(n=16)$ na zona rural, na EEEF Antônio Silveira, foram entrevistados 144 alunos, destes 90\% $(n=129)$ residem na zona urbana e 10\% $(n=15)$ na zona rural, sendo as características semelhantes em ambas às escolas amostradas.

Em relação ao gênero da população amostrada, na EMEF Dr. Flory Druck Kruel, 53\% $(n=84)$ alunos são do gênero feminino e $48 \%(n=76)$ do gênero masculino, já na EEEF Antônio Silveira, 49\% ( $n=71)$ são do gênero feminino e $51 \%(n=73)$ do gênero masculino.

$\mathrm{Na}$ questão 1, perguntou-se aos estudantes se já conheciam o termo Educação Ambiental, no qual, deveriam responder "Sim" ou "Não". Na escola EMEF Dr. Flory Druck Kruel $83 \%(n=133)$ dos alunos já conheciam o tema Educação Ambiental e apenas $17 \%$ $(n=26)$ não conheciam o tema. Na escola EEEF Antônio Silveira $75 \%(n=108)$ dos alunos conheciam o tema e $25 \%(n=36)$ alunos entrevistados não (Figura 1).

A maioria dos alunos reconhece o termo EA, sendo considerada esta resposta como satisfatória. Dados semelhantes encontrados por Costa e Araújo (2009), no Maranhão, com alunos do Ensino Fundamental, de $1^{\text {a }}$ a $8^{\mathrm{a}}$ séries, onde foi observado que $90 \%$ dos alunos entrevistados também tinham o conhecimento do termo EA. 
Figura 1 - Representação gráfica de 7 perguntas presentes no questionário, mostrando a diferença de \% que cada escola obteve nas afirmativas de "Sim"

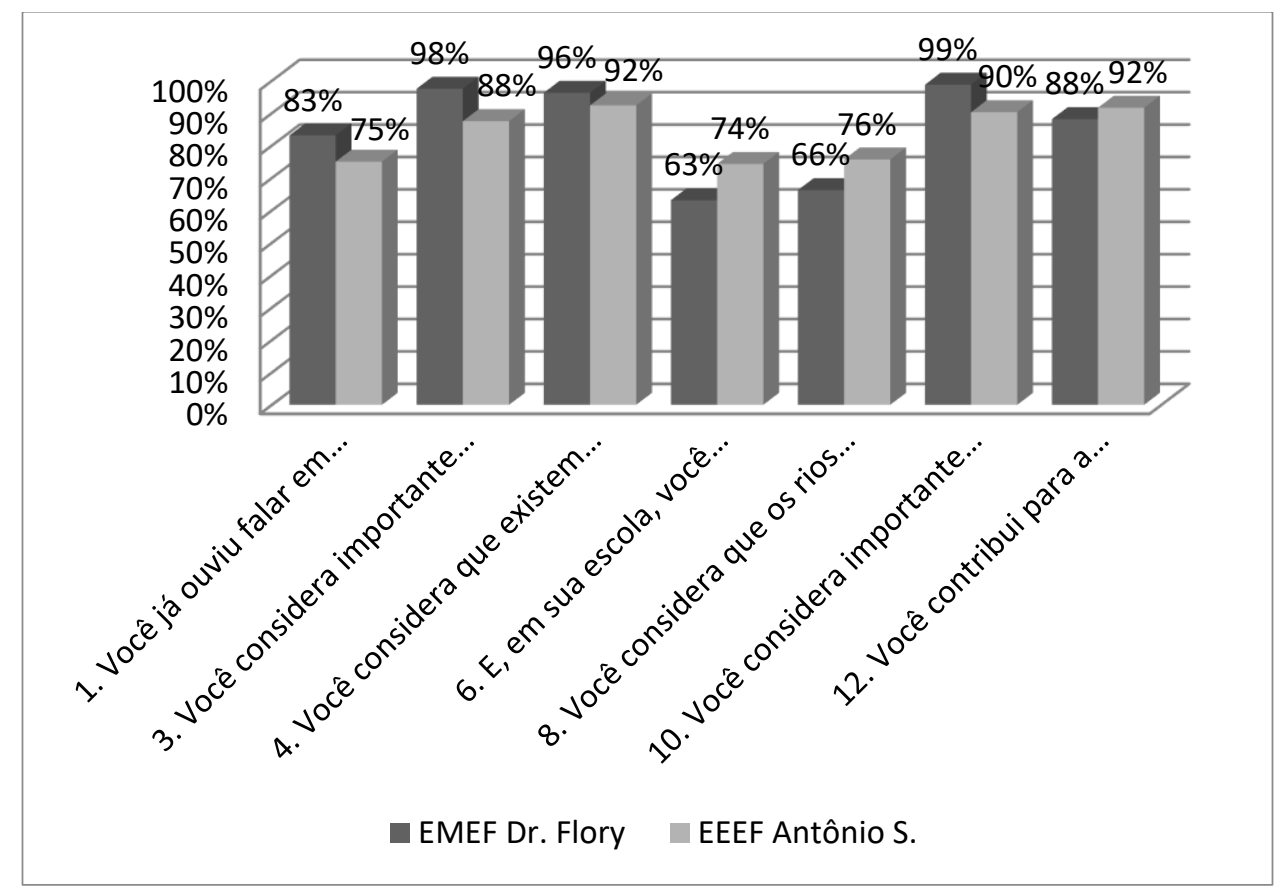

Fonte: Pesquisa

$\mathrm{Na}$ questão 2, os alunos responderam à seguinte pergunta: Quais disciplinas abordam a questão ambiental em sua escola? Na EMEF Dr. Flory Druck Kruel, $72 \%(n=115)$ dos alunos responderam que a disciplina de Geografia aborda questões sobre o meio ambiente, 34\% $(n=55)$ a disciplina de ciências, 1\% $(n=2)$ as disciplinas de religião, português e história, $12 \%(n=19)$ todas as disciplinas abordam o tema e apenas $3 \%(n=4)$ responderam que nenhuma disciplina aborda o tema (Figura 2).

Na EEEF Antônio Silveira, dos alunos entrevistados $65 \%(n=94)$ responderam que a disciplina de geografia aborda questões sobre o meio ambiente, $36 \%(n=52)$ a disciplina de ciências, $0 \%(n=0)$ as disciplina de religião e português, $4 \%(n=6)$ história, 13\% $(n=18)$ responderam que todas abordam o tema e $8 \%(n=12)$ responderam que nenhuma disciplina aborda o tema (Figura 2).

A EA é um tema que deve ser obrigatoriamente abordado nas escolas, é multidimensional, ou seja, pode ser inserido em todas as disciplinas, pois o aprendizado 
está fundamentado na interdisciplinaridade, todas as matérias podem ser desenvolvidas na Educação Ambiental, ou vice-versa (MORIN, 2005).

O ensino sobre o meio ambiente deve contribuir principalmente para o exercício da cidadania, estimulando a ação transformadora, além de buscar aprofundar os conhecimentos sobre as questões ambientais de melhores tecnologias, estimular a mudança de comportamento e a construção de novos valores éticos menos antropocêntricos (BERNA, 2004).

A ligação direta do conceito de EA às disciplinas de Geografia e Ciências tem analogia com as discussões históricas dos professores com as questões ambientais. No entanto, o autor considera uma "mentira" que EA na escola seja discutida somente pelos educadores de disciplinas ligadas a recursos naturais. Esse tema deve se estar presente nos diversos conteúdos curriculares tratados em sala de aula, para que se possam alcançar os objetivos desejados (BARCELOS, 2009).

Figura 2 - Porcentagem das respostas dos alunos em relação à quais disciplinas abordam a questão ambiental, Tupanciretã, RS

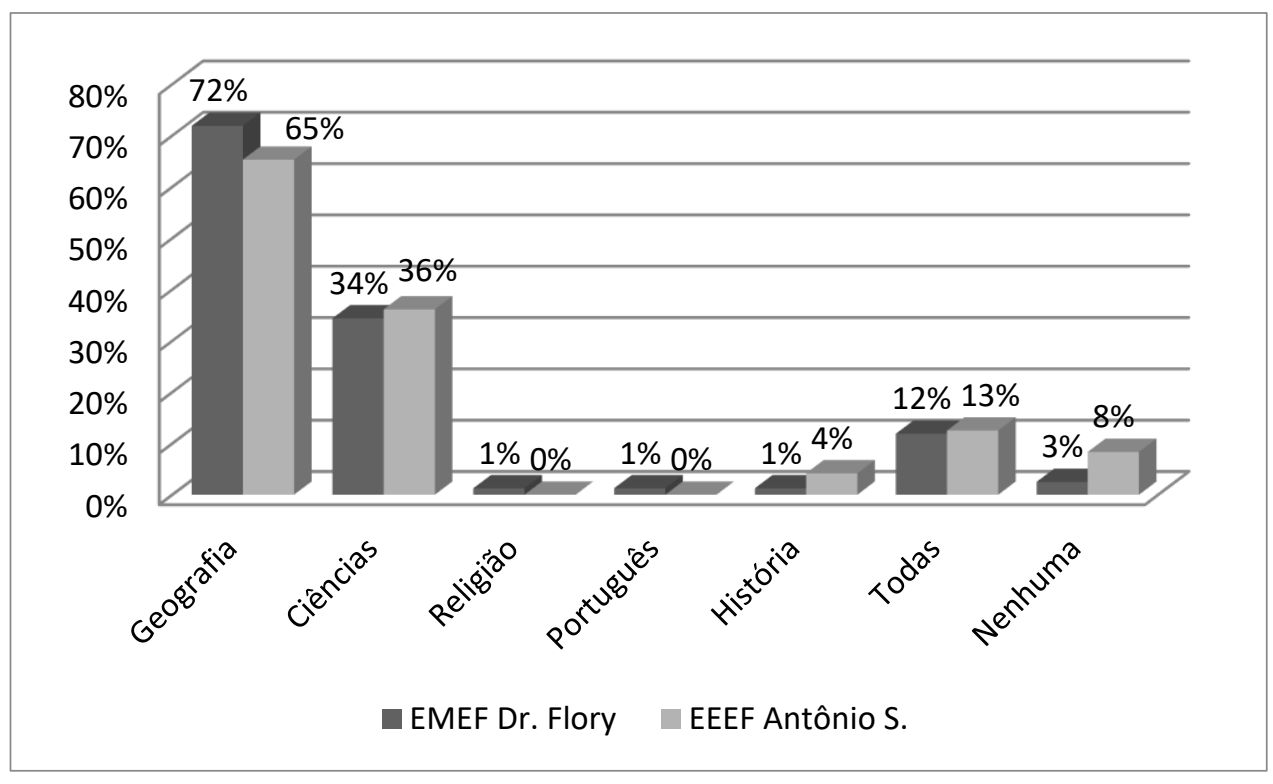

Fonte: Pesquisa 
Na questão 3, perguntou-se sobre a importância da inclusão de uma disciplina de Educação Ambiental na escola. Na EMEF Dr. Flory Druck Kruel, 98\% $(n=155)$ dos alunos consideram importante a existência de uma disciplina de EA e apenas 2\% $(n=5)$ não acham importante. Já na EEEF Antônio Silveira, 88\% $(n=126)$ dos alunos consideraram importante e, $13 \%(n=18)$ dos alunos não acham que a EA precise ser ministrada em sala de aula (Figura 2). Esta questão foi considerada satisfatória.

Gonçalves (1999) defende como procedimento para EA uma "metodologia de ação", de forma a tirar o estudante da posição de mero espectador da realidade que o cerca para colocá-lo como um real participante dessa realidade, permitindo-lhe desenvolver o pensamento consciente, reflexivo e crítico.

É necessário enfrentar as dificuldades quando se quer trabalhar na integra a EA nas escolas. Como defende Dias (1992), "sabe-se que a maioria dos problemas ambientais tem suas raízes em fatores socioeconômicos, políticos e culturais, e que não podem ser previstos ou resolvidos por meios puramente tecnológicos". Daí a grande importância da inserção da EA nas escolas, a fim de conscientizar os alunos e ajudá-los a se tornarem cidadãos ecologicamente corretos.

$\mathrm{Na}$ questão 4, os alunos responderam se consideram a existência de problemas ambientais no município, na EMEF Dr. Flory Druck Kruel, 96\% $(n=154)$ dos alunos consideraram que existem problemas ambientais no município e apenas $4 \%(n=6)$ responderam que não há problemas ambientais. Na EEEF Antônio Silveira, 92\% $(n=133)$ consideraram que existem problemas ambientais e $8 \%(n=11)$ responderam que não há problemas ambientais (Figura 3). Esta questão também foi considerada satisfatória.

O crescente processo de industrialização contribuiu com a degradação ambiental e a redução da qualidade de vida da população em todo o mundo. Os motivos desses problemas se devem tanto ao uso indevido da natureza e dos recursos naturais, quanto à busca de lucros cada vez maiores. Ao longo do tempo o homem provocou transformações no planeta de forma desrespeitosa e pouco inteligente, resultando na contaminação dos 
recursos hídricos, poluição do ar e dos solos, redução dos recursos naturais e aumento da produção de resíduos sólidos (SILVA, 2008).

Os alunos que consideraram que existem problemas ambientais no Município na questão anterior, responderam na questão 5, quais eram os problemas encontrados, podendo marcar mais de uma opção. Na EMEF Dr. Flory Druck Kruel, 96\% $(n=154)$ dos alunos citaram o lixo, $44 \%(n=70)$ as queimadas, $58 \%(n=92)$ o desmatamento, $67 \%$ $(n=107)$ citaram a poluição do $\operatorname{ar}, 59 \%(n=94)$ a poluição das águas e $25 \%(n=40)$ a caça de animais silvestres (Figura 4).

Na EEEF Antônio Silveira, 94\% $(n=135)$ alunos citaram o lixo, 38\% $(n=54)$, as queimadas, $40 \%(n=57)$ o desmatamento, $57 \%(n=82)$ a poluição do ar, $44 \%(n=64)$ a poluição das águas e $31 \%(n=44)$ a caça de animais silvestres (Figura 3 ).

Figura 3 - Porcentagem dos problemas ambientais no Município de Tupanciretã, RS, 2014, segundo os alunos

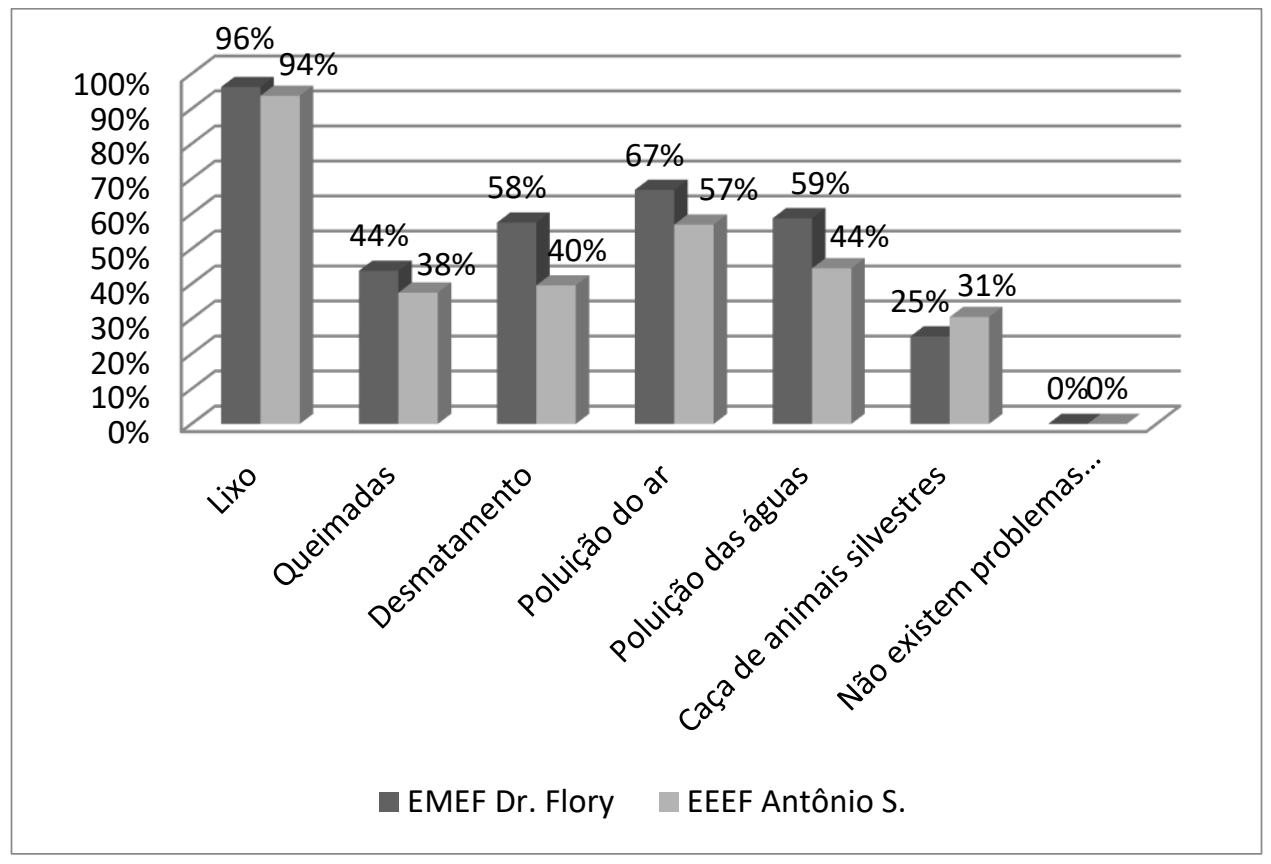

Fonte: Pesquisa

Quando falamos em Meio Ambiente, há uma tendência em "pensar nos inúmeros problemas que o mundo enfrenta com relação à questão ambiental: lixo, poluição, 
desmatamento, espécies em extinção e testes nucleares são, dentre outros, exemplos de situações lembradas". Isso se deve principalmente ao fato de a mídia veicular uma grande quantidade de informações sobre os problemas ambientais. No entanto, para que se possa compreender a gravidade desses problemas e vir a desenvolver valores e atitudes de respeito ao Meio Ambiente é necessário antes de tudo, saber quais as qualidades do ambiente, dessa natureza que se quer defender e porque as pessoas protegem aquilo que amam e valorizam (HERMAN et al., 1992).

A problemática ambiental identificada em situações de ensino-aprendizagem faz a dissociação do contexto socioeconômico e cultural, isto é, da realidade na qual estão inseridos professores e alunos. Isto dificultaria a percepção e compreensão dos mesmos em razão da complexidade do meio em que vivem, sendo, uma possível explicação das razões pelas quais não identificaram os problemas ambientais diretamente na questão anterior (LEFF, 2005).

A questão 6 abordou sobre a presença/ausência de problemas ambientais na escola, sendo que, na EMEF Dr. Flory Druck Kruel 63\% $(n=101)$ dos alunos afirmaram que existe problemas ambientais no ambiente escolar e 37\% $(n=59)$ afirmou que não. Na EEEF Antônio Silveira, $74 \%(n=107)$ consideraram que existem problemas ambientais e $26 \%$ $(n=37)$ dos alunos afirmaram que não (Figura 4).

A questão 7 é um complemento da questão anterior. Questionou quais eram os principais problemas ambientais encontrados na escola, sendo fornecidas alternativas, como lixo, poluição visual e não existem problemas ambientais, podendo marcar mais de uma alternativa.

Na EMEF Dr. Flory Druck Kruel, 62\% $(n=99)$ dos alunos consideraram que existem problemas com o lixo, $56 \%(n=89)$ problema com a poluição visual e $14 \%(n=22)$ afirmou que não existem problemas ambientais. Na EEEF Antônio Silveira, 60\% $(n=86)$ consideraram que existem problemas com o lixo, 57\% $(n=82)$ problema com a poluição visual no ambiente escolar e $11 \%(n=16)$ afirmou que não existem problemas ambientais (Figura 4). 
Figura 4 - Porcentagem dos problemas ambientais citado pelos alunos no ambiente escolar, Tupanciretã, RS, 2014

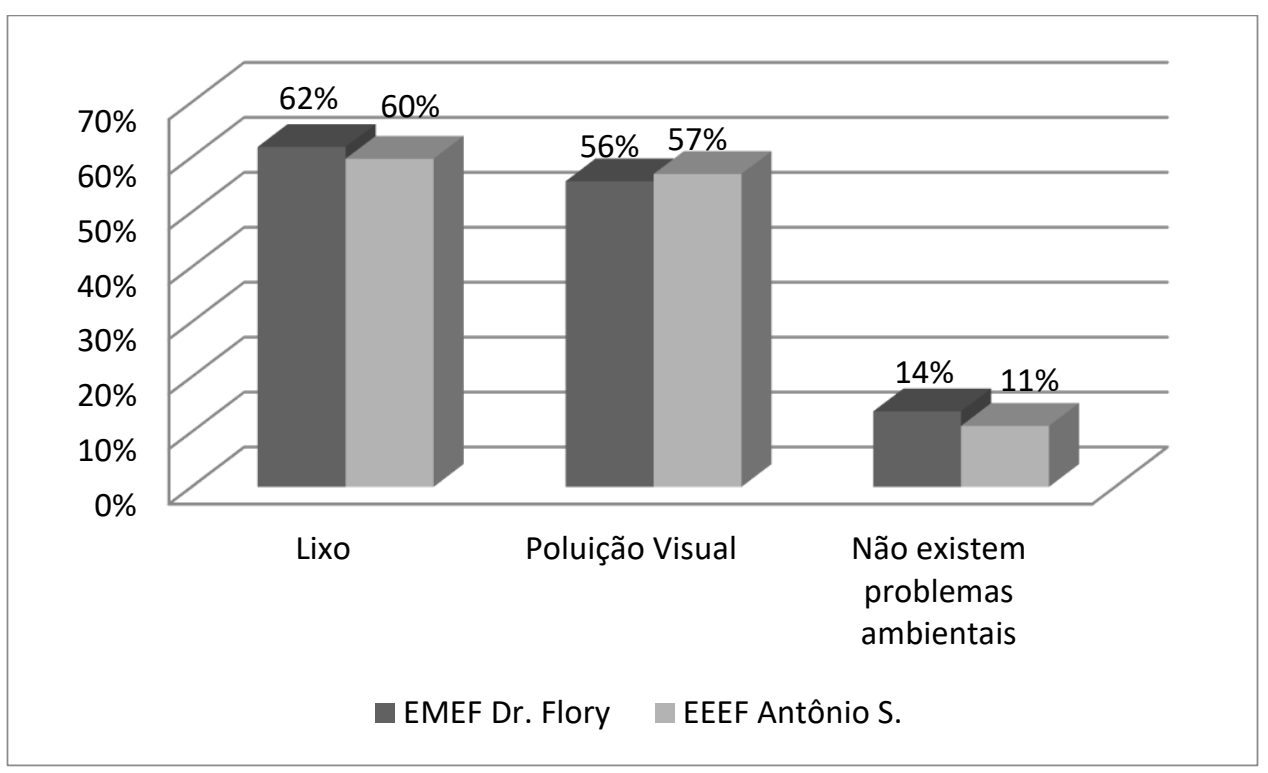

Fonte: Pesquisa

A EA tornou-se hoje uma ferramenta indispensável no combate à destruição ambiental. Pois, é na escola onde deve acontecer uma conversa sobre este assunto, para tentar melhorar as condições do planeta. Sendo assim, surge à necessidade de temas "urgentes e complexos" nos quais os professores têm que trabalhar diariamente em sala de aula com questões voltadas ao meio ambiente, começando pelo ambiente da escola (VIRGENS, 2011). Para conseguir criar uma filosofia conservacionista é necessário que se forme a consciência de, que o ambiente escolar não é de propriedade individual, mas reconhecê-lo como um lugar de todos, por isso, torna-se necessário cuidar dos recursos que podem prejudicar a si mesmo e ao próximo.

Na questão 8, foi questionado se os rios da cidade são poluídos. Na EMEF Dr. Flory Druck Kruel, 66\% ( $n=104)$ afirmaram que os rios estão poluídos e 35\% $(n=56)$ afirmou que não estão poluídos. Na EEEF Antônio Silveira, $76 \%(n=109)$ consideraram que os rios são poluídos e $24 \%(n=35)$ respondeu que não são poluídos (Figura 5 ). 
A questão 9 é um complemento da questão 8, que aborda a situação dos rios do município de Tupanciretã. Com isso, foi questionado qual a principal causa da poluição dos rios, sendo fornecidas alternativas, como lixo, esgoto e que não há problemas. $\mathrm{Na}$ EMEF Dr. Flory Druck Kruel, 46\% $(n=74)$ consideraram que a poluição dos rios é causada pelo lixo, $49 \%(n=79)$ consideraram que é causada pelo derrame de esgoto, e $20 \%(n=32)$ consideraram que os rios do município não estão poluídos. Já na EEEF Antônio Silveira, $45 \%(n=65)$ consideraram que a poluição dos rios é causada pelo lixo, 46\% $(n=66)$ consideraram que é causada pelo derrame de esgoto, e $17 \%(n=25)$ consideraram que os rios do município não estão poluídos (Figura 5).

Figura 5 - Porcentagem dos problemas ambientais que causam poluição nos rios do município de Tupanciretã, RS, 2014

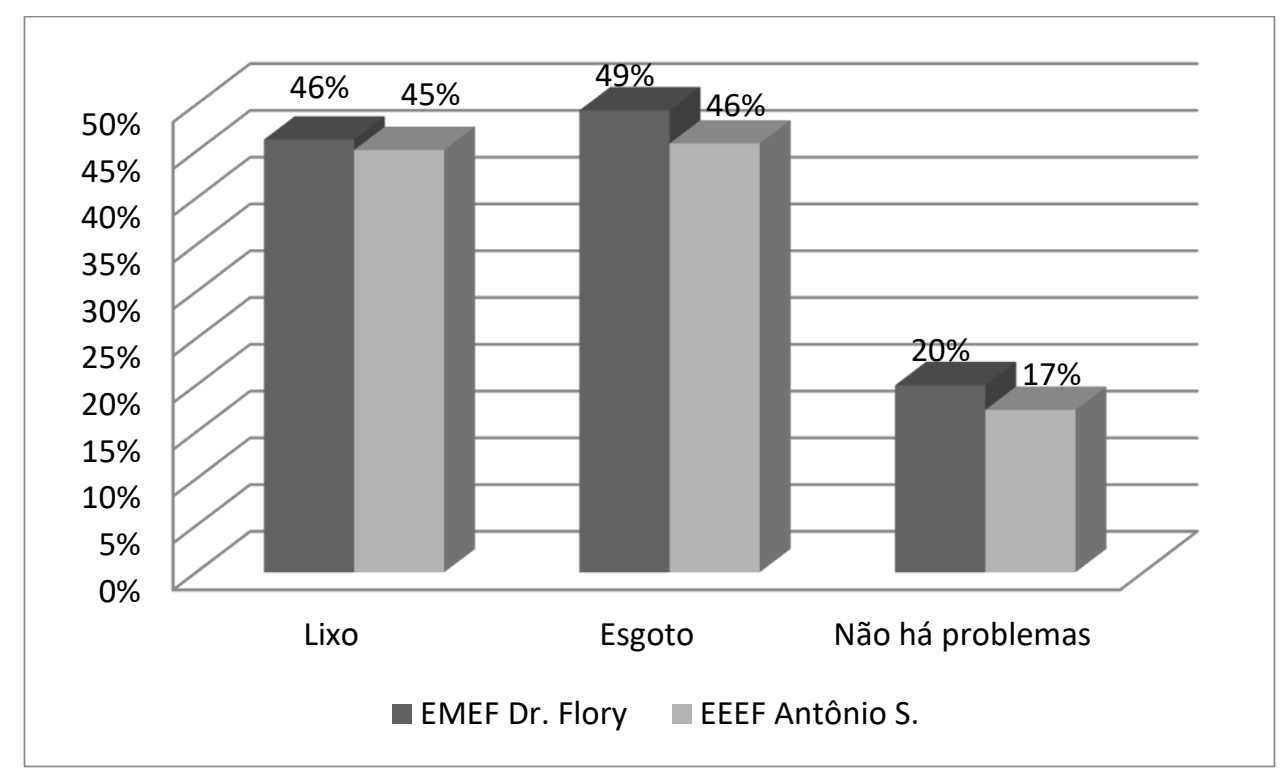

Fonte: Pesquisa

Na questão 10 questionou-se aos alunos se consideram importante a preservação da natureza, na EMEF Dr. Flory Druck Kruel 99\% $(n=158)$ acham que a natureza deve ser preservada e apenas 1\% $(n=2)$ discordam. Já na EEEF Antônio Silveira, 90\% $(n=130)$ acham que a natureza deve ser preservada e 10\% $(n=14)$ discordam (Figura 2). Esta questão foi considerada satisfatória. 
Ainda referente à questão 10 , observa-se que mais de $90 \%$ dos alunos envolvidos na pesquisa, responderam que consideram importante a preservação da natureza. Isso mostra que os jovens estão conscientes da importância de se preservar o Meio Ambiente, pois é um assunto que ganhou destaque mundial devido às grandes catástrofes ocorridas em toda a esfera global (SILVA, 2012).

Perguntou-se na questão 11: Em sua opinião a responsabilidade pelos problemas ambientais é de quem? Foram dadas como alternativa de resposta: governo, escola, todos e ninguém.

Na EMEF Dr. Flory Druck Kruel, 16\% $(n=26)$ afirmaram que a responsabilidade em preservar o meio ambiente é do Governo, nenhum aluno afirmou que a responsabilidade é da escola, $84 \%(n=134)$ afirmou que todos nós devemos preservar e nenhum aluno afirmou que ninguém é responsável pelos problemas ambientais. Já na EEEF Antônio Silveira, 25\% $(n=36)$ afirmaram que a responsabilidade em preservar o Meio Ambiente é do Governo, nenhum aluno afirmou que a responsabilidade é da escola, 75\% $(n=108)$ afirmou que todos nós devemos preservar e nenhum aluno afirmou que ninguém é responsável pelos problemas ambientais (Figura 6).

Esta questão foi considerada satisfatória, pois todos têm responsabilidades individuais de manter o bem-estar da Terra, ou seja, há uma integração e interdependência entre todas as partes que a compõem, incluindo a sociedade. Por isso, é impossível analisar problemas ambientais de forma isolada. A poluição ou qualquer outro dano apresentam reflexos em todo o mundo e não apenas em seus pontos de origem. É fundamental que haja esforços por parte das empresas e do Estado para sua preservação.

Mas, também é necessário que a população colabore com as questões ambientais. Responsabilidade ambiental não é algo isolado e deve envolver diferentes públicos. Essa conscientização tem de começar na base, dentro de casa e na escola, e seguir para o mundo corporativo. Zelar pelo bem-estar do meio ambiente começa com atitudes diárias, como uma evolução da própria educação e do próprio comportamento humano (HERMSDOFF, 2013). 
A questão 12 perguntava o seguinte: "Você contribui para a preservação do Meio Ambiente?", na EMEF Dr. Flory Druck Kruel, 88\% $(n=141)$ dos alunos afirmaram que contribuem com a preservação do Meio Ambiente e 12\% $(n=19)$ disseram que não contribuem. Já na EEEF Antônio Silveira, 92\% $(n=132)$ contribuem e 8\% $(n=12)$ não contribuem (Figura 6).

Figura 6 - Responsabilidade dos problemas ambientais em porcentagem, Tupanciretã, RS, 2014

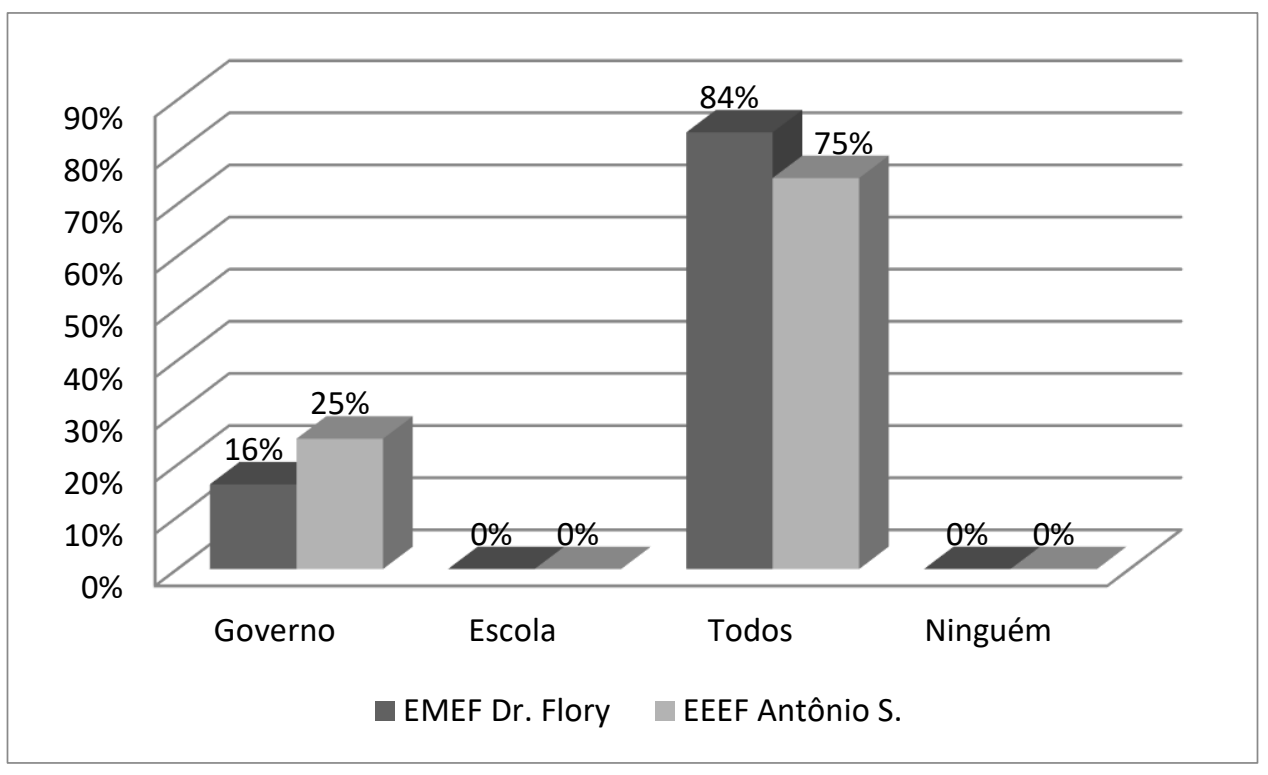

Fonte: Pesquisa

E, por fim a questão 13, única de livre resposta, sendo continuação da questão anterior, indagou os alunos que contribuíam para a preservação do meio ambiente, para descrever algumas atitudes que são adotadas para tal. Para facilitar a análise as respostas foram agrupadas em quatro categorias distintas, sendo elas:

- Lixo no lixo: neste item se agruparam as respostas onde os alunos responderam que faziam a separação do lixo, coleta seletiva, não colocar lixo no chão, acondicionar os resíduos de forma adequada e descartar corretamente. 
- Não fazendo poluição visual (paredes/classes riscadas): neste item se agruparam as respostas que cuidavam para a manutenção do ambiente escolar, como não riscar nas classes, cadeiras e paredes e não colar chiclé embaixo das carteiras.

- Não desmatando: neste item foi considerado, não cortar e podar árvores, não desmatar mato nativo, não queimar resíduos de poda e nem lixo.

- Não poluindo os rios: neste item foram agrupadas todas as respostas sobre economizar água (escovar os dentes, fazer a barba, lavar a louça com a torneira desligada, fazer xixi no banho, usar a máquina de lavar sempre cheia e aproveitar a água para lavar a casa, entre outros), o descarte de resíduos nos mananciais, usar a fossa séptica e sumidouro e não ligar o esgoto doméstico nas tubulações.

Na EMEF Dr. Flory Druck Kruel, 84\% $(n=113)$ dos alunos citaram que preservam jogando o lixo no lixo, $2 \%(n=3)$ não fazem poluição visual (não riscando em paredes e classes), $13 \%(n=17)$ citaram que não fazem desmatamento e $1 \%(n=2)$ não poluindo os rios.

Na EEEF Antônio Silveira, 76\% ( $n=101)$ citaram que preservam jogando o lixo no lixo, $8 \%(n=11)$ não fazem poluição visual, $13 \%(n=18)$ citaram que não fazem desmatamento e $2 \%(n=3)$ não poluindo os rios.

Através dessas respostas, mais precisamente desses quatro agrupamentos, pode-se concluir que há uma tendência à conscientização ambiental por parte dos alunos. Entretanto, também pode-se observar que - respeitada a faixa etária dos entrevistados ainda existem lacunas de compreensão acerca do assunto. O agrupamento das respostas por predominâncias evidencia isso, uma vez que há ações preservativas não mencionadas ou pouco mencionadas pelos estudantes. Ou seja, isto sugere que ainda há vazios na construção do pensamento educativo ambiental dos jovens.

Após a análise dos dados, a categoria "Satisfatória", a qual foi usada para as respostas nas quais os alunos demonstraram ter um conhecimento significativo do assunto abordado, foi a que prevaleceu em todas as questões. Podemos dizer que os alunos percebem e têm consciência dos problemas ambientais do Município e do ambiente 
escolar, porém, não é suficiente para que determinado aluno seja considerado como "consciente ambiental" ou "não".

Mudar alguns hábitos é de extrema importância para que os impactos provocados ao meio ambiente sejam minimizados. Embora esse tipo de mudança pareça difícil, por conta da elevada relação de consumo estabelecida nos centros urbanos, algumas atitudes simples podem contribuir bastante para um melhor uso dos recursos naturais oferecidos pelo planeta.

A conscientização ecológica pode começar dentro da própria casa, com algumas atitudes sustentáveis básicas como: fechar bem as torneiras quando não for mais utilizálas; diminuir o tempo gasto e também reduzir a quantidade de banhos pode ajudar bastante na economia de água, evitando desperdícios; não jogar lixo na rua é algo primordial para evitar problemas mais graves como entupimentos nas redes de esgoto e inundações, entre tantos outros, ajudam e muito na preservação do meio ambiente.

$\mathrm{Na}$ escola podemos implantar projetos com o objetivo de incentivar os alunos a elaborar ações voltadas para o desenvolvimento humano e social, melhoria da qualidade de vida e preservação ambiental. Onde possam aprofundar o conhecimento e avançar para uma ação efetiva relacionada a esse tema, com objetivo de fortalecer o protagonismo dos jovens, como responsáveis pela construção do futuro. Neste quesito podemos citar como exemplo: Horta-Húmus, atividades de horticultura, jardinagem, oficinas de reciclagem de lixo, instituir a semana do meio ambiente, para então, fazer gincanas, palestras e oficinas.

Este trabalho apresentou resultados semelhantes aos encontrados por Oliveira (2006), o qual abordou que os participantes do estudo, de uma maneira geral, sabiam o que precisavam fazer para melhorar o ambiente onde vivem; porém, necessitam de meios mais eficientes que os façam compreender a importância de mudanças de hábitos e atitudes para uma melhor qualidade de vida.

Marczwski (2006), em estudo desenvolvido em Caxias do Sul-RS, observou que os alunos da $5^{a}$ série apresentaram respostas sobre as questões ambientais aquém do 
esperado; nas demais séries do Ensino Fundamental, as respostas estavam de acordo com o esperado.

É essencial que se repense a EA nas escolas tal como ela é concebida nos dias atuais, direcionada apenas para a transmissão de teorias e conhecimentos sobre ecologia. É necessário que ela tenha como objetivo não só os ensinamentos aos alunos sobre a utilização racional dos recursos que a natureza oferece, mas que consiga ultrapassar os muros das escolas, buscando participação permanente da comunidade nas discussões e nas decisões sobre as questões ambientais (MIRANDA, 2008).

A EA pode ser um estimulante espaço para repensar práticas sociais e que o papel dos professores é serem mediadores e transmissores de um conhecimento necessário para que os alunos adquiram base adequada de compreensão do meio ambiente global e local (MIRANDA, 2008).

\section{CONCLUSÕES}

Os resultados demonstram a relevância de se trabalhar a EA a partir da realidade escolar, iniciando pelos conceitos mais básicos de preservação, para que os jovens percebam a importância de pequenas atitudes na preservação ambiental. A escola é considerada o lugar mais adequado para trabalhar a relação homem-ambiente-sociedade, contribuindo para a superação do quadro de degradação ambiental.

De acordo com as escolas analisadas verificou-se que o "conjunto escolar" (professores, alunos, diretores) embora saiba da importância da EA, não existe uma preocupação por parte dessas escolas em trabalhar esses temas, de transformar os estudantes em cidadãos conscientes dos problemas ambientais.

Nesta perspectiva, o desenvolvimento de atividades ligadas à PA e EA deve proporcionar à comunidade uma maior sensibilização em relação ao meio ambiente. Com o propósito de fortalecer o exercício da cidadania e as relações interpessoais com a natureza, acelerando o desenvolvimento de novas atitudes capazes de produzirem novas ações coerentes com a sustentabilidade ambiental, cultural, econômica, social e espacial. 
A EA no ensino fundamental ajuda a conscientizar à preservação. A criança aprende desde cedo que precisa preservar, pois a vida do planeta depende de pequenas ações individuais que fazem a diferença ao serem somadas. As pequenas atitudes, quando somadas proporcionam a transformação do meio no qual habita e reside. Assim, ao crescer, torna-se um transformador de atitudes e um multiplicador de ações benéficas ao ambiente.

O meio ambiente em que estamos inseridos está pedindo novos olhares sobre ele. No entanto, se faz necessário estudar mais sobre esses novos olhares, principalmente nas escolas, onde tudo começa, porque, para os adultos, que já têm seus pensamentos arraigados, a possibilidade de mudança é pequena, infelizmente, mas isso não significa deixar de lado os projetos ambientais onde todos estão inseridos.

\section{REFERÊNCIAS}

ABREU, Raphael Lorenzeto de. Localização de Tupanciretã. Wikipedia, 2006. Disponível em: https://pt.wikipedia.org/wiki/Tupanciret\%C3\%A3. Acesso em: 31 jan. 2018.

BARCELOS, Valdo. Educação ambiental: sobre princípios, metodologias e atitudes. Petrópolis: Vozes, 2009.

BERNA, Vilmar. Como fazer educação ambiental. 2. ed. São Paulo: Paulus, 2004.

BORTOLON, Brenda; MENDES, Marisa Schmitt Siqueira. A Importância da Educação Ambiental para o Alcance da Sustentabilidade. Revista Eletrônica de Iniciação Científica, Itajaí, v. 5, n.1, p. 118-136, 2014.

COSTA, Cristiano Cunha; MAROTI, Paulo Sérgio. Percepção ambiental de docentes em escola rural no estado de Sergipe. REMOA/UFSM, v. 11, n. 11, p. 2379-2388, jan./abr. 2013.

COSTA, Ângela de Cassia; ARÁUJO, Andrea. Percepção ambiental dos alunos de uma escola da rede pública municipal da cidade de Raposa - MA. Recanto das letras, Maranhão, 2009. Disponível em: <http://recantodasletras.uol.com.br/trabalhosacademicos/1759863>. Acesso em: 20 dez. 2017.

DIAS, Genebaldo Freire. Educação ambiental: princípios e práticas. 3. ed. São Paulo: Gaia, 1992. DIAS, Genebaldo Freire. Educação Ambiental: princípios e práticas. 9. ed. São Paulo: Gaia, 2004. 
FERNANDES, R. S. et al. O uso da percepção ambiental como instrumento de gestão em aplicações ligadas às áreas educacional, social e ambiental. In: ENCONTRO DA ANPPAS, 2., 2004, Indaiatuba. Anais eletrônicos... Belém: Associação Nacional de Pós-Graduação e Pesquisa em Ambiente e Sociedade, $2004 . \quad$ Disponível em: http://www.redeceas.esalq.usp.br/noticias/Percepcao_Ambiental.pdf. Acesso em: 31 jan. 2018.

FIGUEIRÓ, P.S. Educação para a Sustentabilidade em cursos de graduação em Administração: proposta de uma estrutura analítica. 2015. 262 f. Tese (Doutorado em Administração). Universidade Federal do Rio Grande do Sul, Porto Alegre, 2015. Disponível em: http://www.lume.ufrgs.br/bitstream/handle/10183/131866/000982132.pdf?sequence=1.

Acesso em: 26 jan. 2016.

GONÇALVES, Wantuelfer. Florestas urbanas: ação ambiental. Porto Alegre: Ed. Cinco Continentes, 1999.

HERMAN, M. L. et al. Orientando a criança para amar a terra. São Paulo: Augustus, 1992.

HERMSDOFF, S. Responsabilidade ambiental é de todos. FGV: Centro de estudos em Sustentabilidade, jul. 2013. Disponível em: http://www.pagina22.com.br/index.php/2013/07/responsabilidade-ambiental-e-de-todos/. Acesso em: 2 fev. 2018.

IBGE - Instituto Brasileiro de Geografia e Estatística. Dados do Município. Prefeitura Municipal de Tupanciretã, $\quad$ Tupanciretã, 2010.2 Disponível em: <http://www.tupancireta.rs.gov.br/pagina/id/63/?dados-do-municipio.html. Acesso em: 31 jan. 2018.

LEFF, Enrique. Saber ambiental: sustentabilidade, racionalidade, complexidade, poder. Petrópolis: Vozes, 2005.

MARCZWSKI, M. Avaliação da percepção ambiental em uma população de estudantes do ensino fundamental de uma escola municipal rural: um estudo de caso. 2006. $188 \mathrm{f}$. Dissertação (Mestrado em Ecologia). Universidade Federal do Rio Grande do Sul, Porto Alegre, 2006.

MEDEIROS, A. B. et al. A Importância da educação ambiental na escola nas séries iniciais. Revista Faculdade Montes Belos, v. 4, n. 1, set. 2011.

MIRANDA, A. M. Percepção ambiental: O despertar para o conhecimento científico através de uma horta educativa. In: $1^{\circ}$ Encontro de Educação do Colégio Gonçalves Dias, 2008, Nova Iguaçu/RJ. Anais eletrônicos... Nova Iguaçu, 2008. Disponível em: http://novaiguacu.com.br/eegd/2008/percepcao_ambiental.pdf. Acesso em: 2 fev. 2018. 
MORIN, Edgar. Os sete saberes necessários à educação do futuro. 11.ed. São Paulo: Cortez, 2005.

OLIVEIRA, N. A. S. A percepção dos resíduos sólidos (lixo) de origem domiciliar, no bairro Cajuru - Curitiba-PR: um olhar reflexivo a partir da educação ambiental. 2006. $174 \mathrm{f}$. Dissertação (Mestrado em Geografia). Universidade Federal do Paraná, Curitiba, 2006.

PEREIRA, E. M.; FARRAPEIRA, C. M. R.; PINTO, S. L. Percepção e educação ambiental sobre manguezais em escolas públicas da Região Metropolitana do Recife. Rev. eletrônica Mestr. Educ. Ambient., v.17, 2006.

SILVA, D. G. A importância da educação ambiental para a sustentabilidade. 2012. Trabalho de Conclusão de Curso (Curso de Ciências Biológicas). Faculdade Estadual de Educação, Ciências e Letras de Paranavaí, São Joaquim, 2012.

SILVA, F. V. P. A educação ambiental na formação da cidadania. 2008. Trabalho de Conclusão de Curso (Curso de Ciências Biológicas). Centro Universitário Metodista Izabela Hendrix, Belo Horizonte, MG, 2008.

SILVA, V. M. A importância da preservação e conscientização do uso das águas na comunidade de Paulista - PB. 2012. 55 f. Monografia (Curso de Licenciatura em Ciências Exatas). Universidade Estadual da Paraíba, Patos, Paraíba, 2012.

VASCONCELOS, F. A. L. Análise comparativa da percepção ambiental e conhecimento de alunos da rede pública e particular da Região Metropolitana do Grande Recife acerca do tema "Ambientes Recifais". 2005. 70 f. Monografia (Bacharelado em Ciências Biológicas). Universidade Federal Rural de Pernambuco, Recife, 2005.

VIRGENS, R. A. A educação ambiental no ambiente escolar. 2011. Monografia (Curso de Licenciatura em Biologia). Consórcio Setentrional de Educação a Distância - Universidade de Brasília e Universidade Estadual de Goiás, Brasília, 2011. 